\title{
SAFELY CONDUCTING AIRPORT SURFACE TRAJECTORY-BASED OPERATIONS
}

\author{
Denise R. Jones, Lawrence J. Prinzel, III, Randall E. Bailey, and Jarvis J. Arthur, III \\ National Aeronautics and Space Administration, Hampton, VA \\ James R. Barnes, Booz Allen Hamilton Engineering Services, LLC, Hampton, VA
}

\begin{abstract}
A piloted simulation study was conducted at the National Aeronautics and Space Administration (NASA) Langley Research Center (LaRC) to evaluate the ability to safely conduct surface trajectory-based operations (STBO) by assessing the impact of providing traffic intent information, conflict detection and resolution (CD\&R) system capability, and the display of STBO guidance to the flight crew on both head-down and head-up displays (HUD). Nominal and off-nominal conflict scenarios were conducted using 12 airline crews operating in a simulated Memphis International Airport terminal environment. The flight crews met their required time-of-arrival at route end within 10 seconds on 98 percent of the trials, well within the acceptable performance bounds of 15 seconds. Traffic intent information was found to be useful in determining the intent of conflict traffic, with graphical presentation preferred. The CD\&R system was only minimally effective during STBO because the prevailing visibility was sufficient for visual detection of incurring traffic. Overall, the pilots indicated STBO increased general situation awareness but also negatively impacted workload, reduced the ability to watch for other traffic, and increased head-down time.
\end{abstract}

\section{Introduction}

The Next Generation Air Transportation System (NextGen) vision transforms the air transportation system to meet the projected growth in aircraft operations expected in the 2025 time-frame in a safe, efficient, and reliable manner. Emerging NextGen operational concepts [1], such as trajectory-based airborne and surface operations, equivalent visual operations, and high-density arrival and departure operations, represent a revolutionary approach to air traffic management. A net-centric infrastructure is envisioned, enabling a safe and efficient airport surface environment by providing the information necessary to improve flight deck and ground vehicle situational awareness through display of traffic, airport moving maps (AMM), and proactive alerts of runway incursions and surface traffic conflicts.

Surface Trajectory-Based Operations (STBO) is a NextGen operational concept aimed at improving the efficiency and safety of surface operations at high-density airports. Surface movement management tools will utilize improved surveillance, environmental and operational conditions, and other information to sequence aircraft for departure, issue conflict-free time-based taxi routes, monitor taxi conformance, and revise taxi plans as necessary $[2,3]$. The taxi routes are intended to be transmitted through data communications protocols and displayed to the flight crew on a flight deck surface movement display [4-8].

Although STBO is intended to eliminate surface traffic conflicts, on-board conflict detection and resolution (CD\&R) systems will provide an additional, protective safety layer for NextGen operations in the event that tactical or strategic situation awareness is not sufficient or human errors or blunders occur. The National Aeronautics and Space Administration (NASA) has developed a CD\&R concept that leverages advances in flight deck displays and technologies to promote enhanced surface and airborne traffic awareness with associated flight deck alerting concepts for safety assurance [9-13]. These concepts employ continual ownship and traffic data monitoring and algorithms to detect potential conflicts on the runway and during taxi operations for aircraft and surface vehicles. NASA has also conducted initial research on groundbased CD\&R for air traffic control (ATC) STBO decision support tools $[14,15]$ and the integration of ground- and flight deck-based CD\&R for STBO [16].

U.S. Government work not protected by U.S. copyright 
A high-fidelity full-motion piloted simulation study was conducted to evaluate the ability to safely conduct STBO by assessing the impact of providing traffic intent information, flight deck-based CD\&R system capability, and the display of STBO guidance to the flight crew on both head-down and head-up displays (HUD). This paper describes the test set-up, method, and quantitative and qualitative results.

\section{System Description}

\section{Simulator}

This research was conducted in the Research Flight Deck (RFD) simulator at NASA Langley Research Center (LaRC) (Figure 1) which is a highfidelity, six degrees-of-freedom motion-based large commercial aircraft simulator with full-mission capability and advanced glass flight deck displays. Operations were conducted at the Memphis International (KMEM) airport. The out-the-window (OTW) scene included realistic taxiways and runways with appropriate markings, airport lighting, and other aircraft in simulated visibility conditions and provided approximately $20 / 40$ visual acuity with a collimated $200^{\circ}$ horizontal by $40^{\circ}$ vertical field of view at 26 pixels per degree resolution.

The RFD is equipped with dual $46^{\circ}$ horizontal $\mathrm{x}$ $34.5^{\circ}$ vertical field-of-view commercial HUDs; however, only the HUD located on the left or captain's side was utilized.

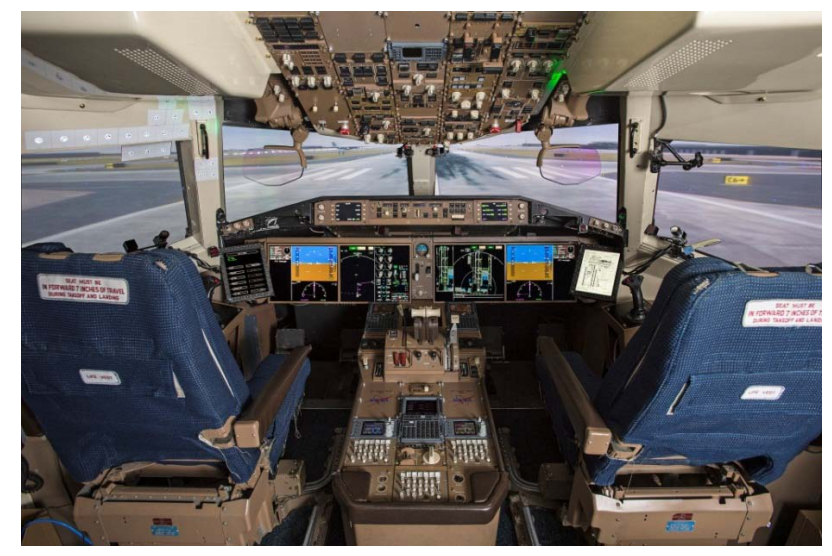

\section{Figure 1. RFD Flight Deck}

As shown in Figure 1, the simulator had four large main instrument panel displays referred to as: (left to right) pilot's Primary Flight Display (PFD), pilot's Navigation Display (ND), co-pilot's ND, and co-pilot's PFD. Each display panel had 13.25 inch $\mathrm{x}$ 10.5 inch viewable area at $1280 \times 1024$ resolution.

Two Electronic Flight Bags (EFBs) were installed. Each provided a display resolution of 1024 x 768 pixels over a 10.4 inch diagonal area. The EFBs were mounted outboard of the PFDs and were located within the pilot's primary field-of-view as per the Advisory Circular (AC) 25-11A [17].

\section{Flight Deck Displays}

The PFD, ND, and HUD formats mimicked current state-of-the-art production aircraft. Additions were made to accommodate study objectives.

\section{Primary Flight Display}

The PFD included an ATC message area on the outboard portion of the panel showing incoming and outgoing ATC data-link communications in textual format. Incoming messages were color-coded green while outgoing messages were white. All messages were time-stamped.

\section{Navigation Display}

The ND was split, showing a half-screen map display and half-screen Engine Indication and Caution Alerting System. An AMM was not shown on the ND.

\section{Head-Up Display}

Standard on-ground HUD symbology was used. The ground speed was displayed in the lower left. The STBO advised speed was shown above the ground speed.

\section{Electronic Flight Bag Display}

The EFB was used for communications, charts, checklists, and AMM through either a bezel button or touch screen interface.

The communications function was used to display and respond to ATC data-link messages. An incoming ATC message was displayed in green on the EFB and also on the PFD. Once the message was acknowledged, the message color changed to white on the EFB and an acknowledgement message ('WILCO') was displayed on the PFD.

The charts function provided the ability to display arrival, approach, departure, and airport 
charts. Pan/zoom (full page, half of the diagram, one fourth of the diagram) capability was provided.

The checklists function provided the capability to display all aircraft checklists.

The EFB was the only location used to display the AMM. Range control for the AMM was provisioned at 0.4 nautical miles $(\mathrm{nm}), 0.8 \mathrm{~nm}, 1.6$ $\mathrm{nm}$, and $3.2 \mathrm{~nm}$. The basic AMM display included an airport layout showing runways, taxiways, and buildings. Surface (tan) and airborne (cyan) traffic icons were shown along with the ownship position (white chevron). The AMM used a KMEM airport geographic database developed to RTCA standards [18]. In this document, all figures of the AMM are shown without the surrounding EFB bezel button structure. Specific AMM configurations used for the study are provided in the Test Method section below.

\section{Air Traffic Control Simulation}

ATC instructions and other aircraft requests and replies were simulated via a speech generation system to increase the fidelity of the simulation and provide normal pilot workload demands. The messages were played through the intercom or through the flight deck speaker system when the ownship and simulated traffic reached specified locations or timings to coincide with the scenario task. The subject pilots were asked to provide radio replies as per normal operating procedures. Human back-up was present if additional or unscripted communication or clarification was necessary.

\section{Conflict Detection and Resolution}

A CD\&R system was active during the testing. This system was developed based on Safety, Performance, and Interoperability Requirements (SPR) for Enhanced Traffic Situational Awareness on the Airport Surface with Indications and Alerts (SURF IA) specifications [19] as well as NASA $\mathrm{CD \& R}$ research.

\section{NASA CD\&R Research}

The NASA taxi conflict monitor was designed to detect and alert for ground taxi conflicts in the airport movement area by computing distances between the ownship and traffic, closing speeds, time to closest point of approach and other parameters to determine if criteria and thresholds are met for issuing alerts [20].

\section{Indications and Alerts}

Indications and alerts (IA) notify the flight crew of potentially hazardous situations. IA specifications are defined in [19]. This study focused on STBO taxi operations and only included taxi conflicts; therefore, indications were not generated and, consequently, will not be discussed further in this document.

Alerts identified potential collision hazards which require immediate flight crew awareness and may require timely action or response. A two-level alerting scheme was utilized.

Caution alerts were generated for conditions that required immediate flight crew awareness and subsequent flight crew response. A caution alert was displayed on the AMM as an enlarged yellow traffic symbol surrounded by a yellow circle for the relevant traffic, an identification tag and ground speed in knots, and a yellow line around the relevant runway, if applicable. An alert message ("Caution, Traffic") was displayed at the bottom of the AMM in yellow text along with the estimated distance to the traffic. An audible annunciation was also made ("Caution, Traffic, Caution, Traffic") (Figure 2).

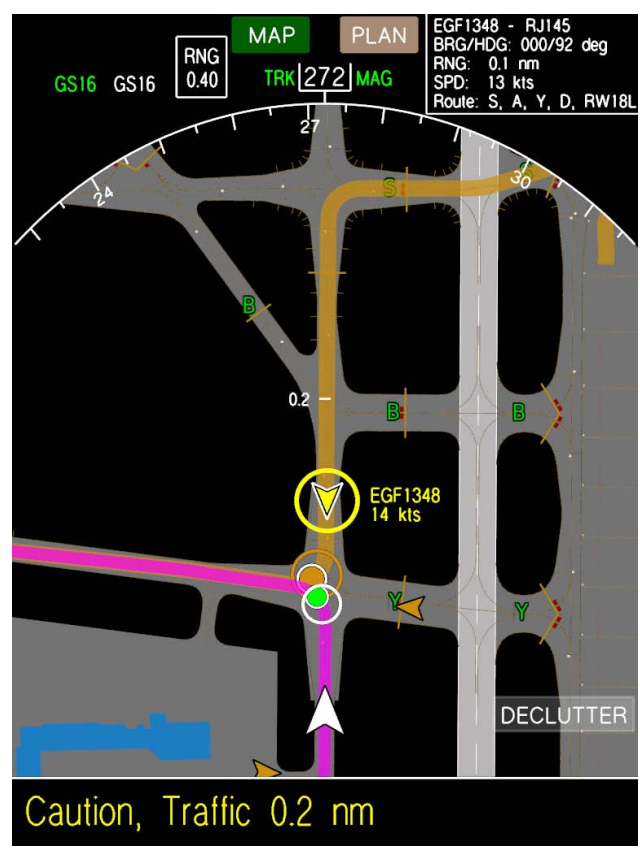

Figure 2. AMM Showing Caution Alert 
Warning alerts were issued for conditions that required immediate flight crew awareness and immediate flight crew response. Warning alerts could occur without preceding caution alerts. A warning alert was displayed in the same manner on the AMM as a caution alert, except the warning was associated with the color red, a square was used to surround the traffic symbol, and the alert message was "Warning, Traffic" (Figure 3).

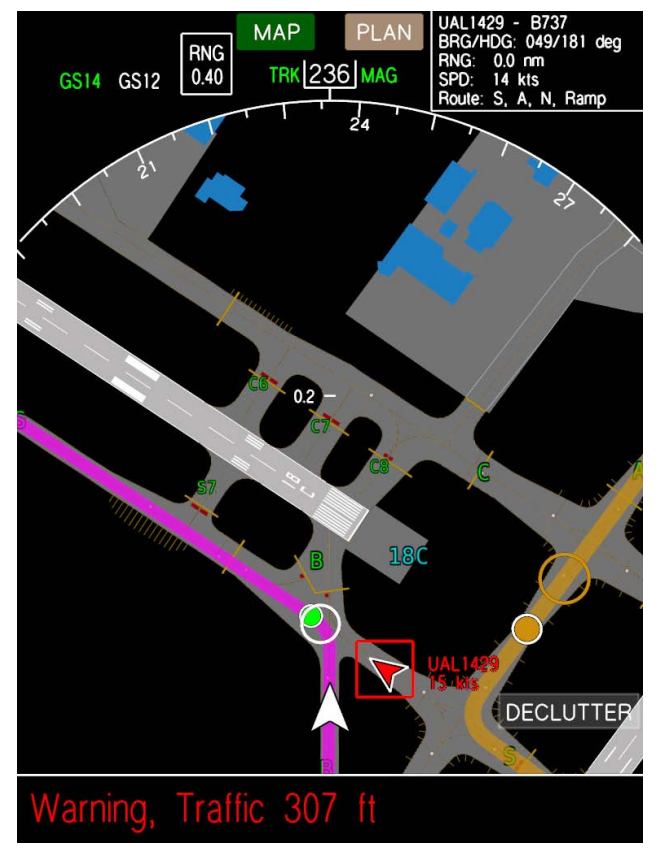

Figure 3. AMM Showing Warning Alert

\section{Surveillance Data}

The quality and accuracy of reported traffic surveillance data are critical to the integrity of the AMM traffic displays and the CD\&R capability. The traffic position accuracy was simulated as dependent upon the Global Positioning System (GPS) measurement errors. A Gauss-Markov process modeled the time correlation between successive position measurement errors [21]. It was assumed that ADS-B would be used as the means for transmitting (ADS-B Out) and receiving (ADS-B In) these GPS-based aircraft surveillance data. Although ADS-B transmission qualities and effects were not modeled for this study, the traffic positional data was updated at one hertz to simulate ADS-B transmission rates. Latency effects, transmission line-of-sight, bandwidth blockage, and vertical position accuracy were not modeled.
The Navigation Accuracy Category for Position (NACp) describes the accuracy of positional information. NACp values range from 0 to 11 [22]. The NACp categories of 8 and higher are listed in Table 1 with their associated horizontal Estimated Position Uncertainty (EPU) values.

Table 1. NACp Horizontal Accuracy Bound

\begin{tabular}{|c|c|}
\hline NACp & $\begin{array}{l}\text { 95\% Horizontal Accuracy - Estimated } \\
\text { Position Uncertainty (EPU) }\end{array}$ \\
\hline 8 & EPU $<92.6 \mathrm{~m}(0.05 \mathrm{~nm}, 305.6 \mathrm{ft})$ \\
\hline 9 & EPU $<30 \mathrm{~m}(99 \mathrm{ft})$ \\
\hline 10 & EPU $<10 \mathrm{~m}(33 \mathrm{ft})$ \\
\hline 11 & EPU $<3 \mathrm{~m}(9.9 \mathrm{ft})$ \\
\hline \multicolumn{2}{|c|}{ Both DO-289 (Minimum Aviation System }
\end{tabular}

Performance Standards for Aircraft Surveillance Applications) [23] and DO-322 (SPR for Airborne Traffic Situational Awareness for Surface Operations (ATSA-SURF) Application) [24] define the minimum requirement for horizontal position accuracy for depiction of ground traffic on an AMM to be at least 30 meters $(\mathrm{m})$ within $95 \%$ containment bounds, equivalent to NACp 9. Requirements for other navigation parameters are also specified in these reports but will not be addressed in this paper.

The SURF IA SPR has proposed horizontal position accuracy requirements [19] for the SURF IA function. Through analysis, the SPR identified that to meet safety requirements, horizontal position accuracy when on the airport surface needs to be at least $10 \mathrm{~m}$ within $95 \%$ containment bounds (NACp 10) to allow alerts to be issued for traffic at virtually all airports in the National Airspace System.

Traffic positioning accuracies equivalent to NACp 9, 10, and 11 were used. Truth data, with no accuracy errors, was also recorded. The accuracy levels (e.g., NACp 9, NACp 10, etc.) were controlled for individual traffic.

\section{STBO Guidance Algorithm}

For all ownship routes, a nominal taxi trajectory was created. The trajectory was built using the ownship's performance and loading, assuming relatively low visibility $(1,800$ feet $(\mathrm{ft}))$, and planning a nominal acceleration and deceleration at the start, end, and around turns to create a planned, distance, 
time, and speed taxi profile. The profile assumed 15 knots (kts) in straight taxi segments and a minimum of $5 \mathrm{kts}$ through the turns. The designed trajectories were flight-checked for reasonableness by several check-pilots.

STBO guidance information was computed using a feedback control law with actual performance compared against these desired trajectories to provide an advised ground speed (GS). The control law used intermediate waypoints along the route to implicitly obtain STBO compliance along the route as well as the final Required Time-of-Arrival (RTA). The intermediate waypoint performance was not explicitly shown nor instructed to the crews, but it was part of the control law in computing the advised speed for the crews.
The advised speed was limited to maximum and minimum values: $30 \mathrm{kts}$ and $10 \mathrm{kts}$, respectively, on straight-aways and $10 \mathrm{kts}$ and $4 \mathrm{kts}$ in turns.

The crew was instructed that the advised GS (displayed in green at top left of AMM) was to be used as a reference for reaching the RTA point (green diamond near end of route) at the RTA (displayed in green at bottom of AMM display) (Figure 4). It was not required that pilots track the advised GS precisely. Acceptable performance was met if the time-of-arrival at the RTA end point was within +/15 seconds of the RTA. The Estimated Time-ofArrival (ETA) and seconds early or late was displayed at the bottom of the AMM in white (Figure 4) to give the flight crew additional information on how well they were progressing along the route. If the crew were more than 15 seconds early or late, the words 'EARLY' or 'LATE' would also be displayed at the bottom of the AMM.

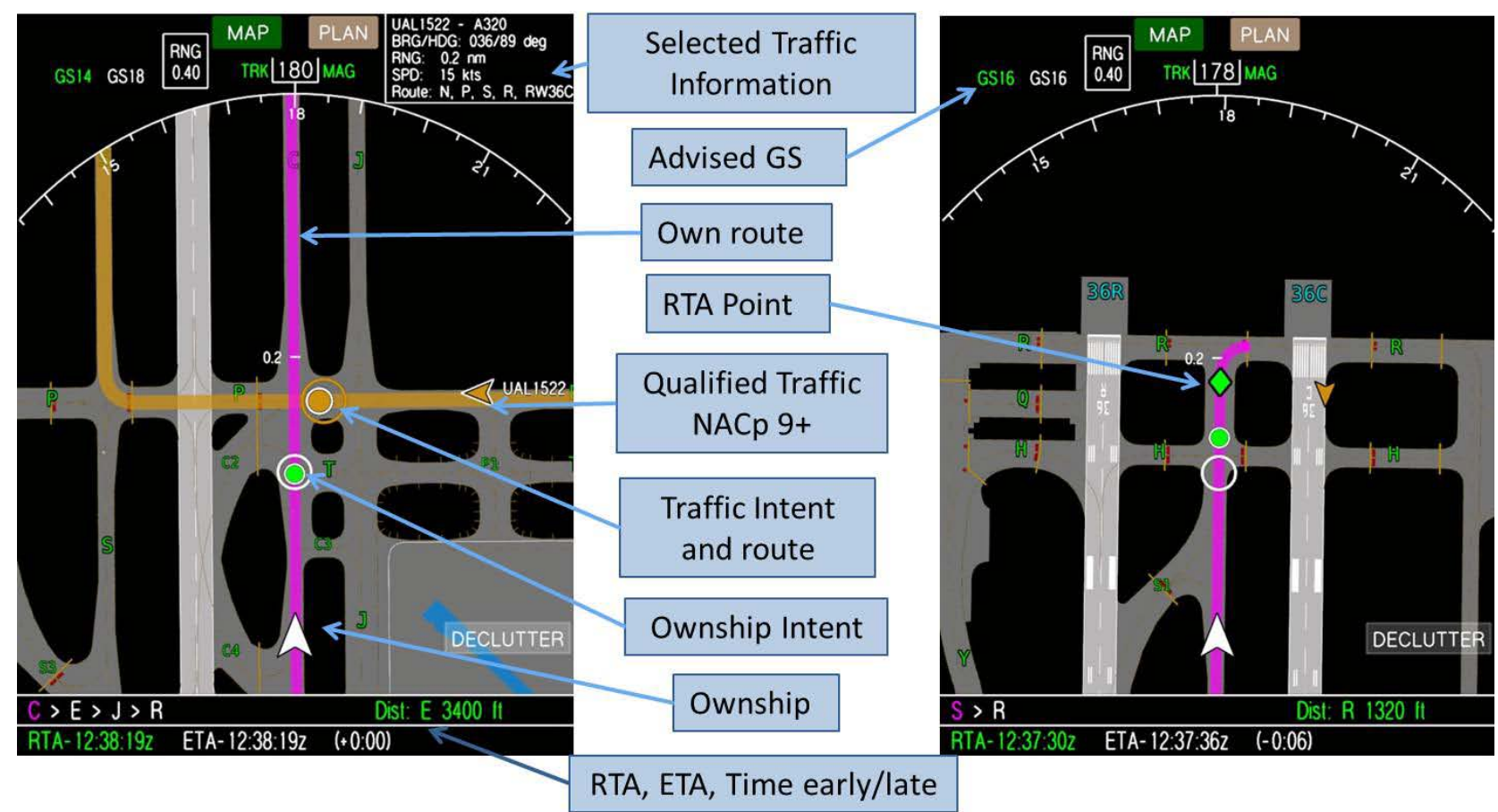

Figure 4. STBO Guidance Information Displayed on AMM

\section{Test Method}

The test objectives were to evaluate the ability to safely conduct STBO by assessing the impact of providing traffic intent information, CD\&R system capability, and the display of STBO guidance to the flight crew on both head-down and head-up displays.
Evaluations were conducted during STBO taxi operations from the ramp to the departure runway utilizing two HUD conditions and two AMM conditions with traffic transmitting various levels of horizontal position accuracy. 


\section{Evaluation Pilots}

Twenty-four commercial pilots participated. The test subjects were paired by airline and role (Captain, First Officer) to ensure crew coordination and cohesion with regard to terminal and surface standard operational procedures. All pilots held an Airline Transport Pilot rating. The Captains had an average of over 17,000 flight hours with 25 years of commercial experience. The First Officers had an average of over 13,000 flight hours with 20 years of commercial experience.

\section{Display Conditions}

Symbology was added to the basic AMM format and to the HUD to enable the flight crew to efficiently and safely conduct STBO taxi operations. Two AMM and two HUD display conditions were evaluated as described below.

The Map C condition consisted of a basic AMM format and added the display of textual STBO guidance information, selected traffic information, and the ownship cleared taxi route as a magenta line.

The crew had the capability to obtain selected traffic information (aircraft identification; bearing, heading, and range from ownship; ground speed; and cleared taxi route) by touching the traffic icon symbol on the AMM. By reading the traffic's cleared taxi route, the crew could figure out route conflicts with the ownship's cleared taxi route.

The Map $D$ condition was created by the addition of graphical ownship and traffic intent and graphical traffic route (Figure 4).

In this condition, when selected traffic information was selected, the traffic's cleared route was also displayed graphically in tan (Figure 4).

Graphical intent information was also displayed for both the ownship and selected traffic using solid and open circles. The solid traffic intent symbol gave an indication of position required in 30 seconds to achieve the RTA. The open trend symbol gave an indication of the position of the aircraft in 30 seconds based on the planned speed required to meet the RTA. When the trend symbol surrounded the intent symbol, as shown in the left AMM image in Figure 4, the aircraft was precisely tracking the STBO clearance. If the trend symbol was displayed behind the intent symbol, as shown in the right AMM image in Figure 4, the aircraft was behind schedule and may reach the RTA point late. If the trend symbol was displayed ahead of the intent symbol, the aircraft was ahead of schedule and may reach the RTA point early.

The graphical taxi routes and intent and STBO status information provided the capability to view the route conflicts at-a-glance rather than having to interpret the textual clearance in the information area to determine whether there was a potential conflict. By viewing the traffic's intent and trend symbols, it was obvious when a collision was predicted; the ownship and traffic intent and trend symbols overlaid each other.

The HUD was used during a portion of the STBO taxi scenarios. The standard HUD surface symbology (described above) was used with the addition of the advised GS (displayed above the GS). This allowed the Captain to remain heads-up to view the STBO guidance. When test conditions did not require use of the HUD, the HUD was stowed so it would not be an influence or obstruction.

\section{Test Matrix}

A total of six trials (four nominal, two offnominal) were conducted with each crew. All trials were conducted in daytime $1,800 \mathrm{ft}$ visibility. Traffic was transmitting position accuracy ranges from NACp 9 to NACp 11; therefore, all the airport traffic was displayed on the AMM.

Nominal trials were conducted to evaluate the flight crew's performance in following STBO taxi guidance using HUD and AMM symbology. Two AMM conditions (Map C and Map D) were evaluated between subjects, using two HUD display conditions (HUD or no HUD) during departure taxi scenarios, for a total of four nominal trials.

Off-nominal trials were conducted between subjects to evaluate collision avoidance capability during STBO. The focus of the off-nominal scenarios was to determine the usefulness of traffic intent information for taxi collision avoidance and to determine the usefulness of CD\&R for collision avoidance during STBO. Each crew completed two off-nominal trials as Test Runs 3 and 6 of six trials. 
The HUD was not utilized during the off-nominal trials. A detailed description of the off-nominal scenarios is given below. Each crew evaluated these two scenarios using either the Map C or D condition with conflict traffic transmitting either NACp 9 or NACp 10 position accuracy; therefore, three data points were collected for each combination of conditions. Alerts were not issued for traffic transmitting NACp 9 position accuracy, but were issued for traffic transmitting NACp 10 position accuracy (as per DO-323) [19].

\section{Conflict Scenarios}

Two conflict scenarios were utilized. Every effort was made to produce similar timings; however, a certain amount of variability was naturally introduced due to the maneuvering conducted by the pilot (e.g., taxi speed).

\section{Taxi Head-On Conflict Scenario}

This scenario tested a potential head-on collision if no action were taken because the aircraft were given conflicting STBO taxi clearances.

An approach and departure flow was simulated. Traffic was approaching Runway 18R (Figure 5, orange route) and Runway $18 \mathrm{C}$ (Figure 5, orange dashed route), spaced five $\mathrm{nm}$ apart and staggered between runways. This traffic landed, exited the runway, and taxied to the terminal. There was a departure flow using Runway $18 \mathrm{~L}$ via the magenta and blue colored routes shown in Figure 5.

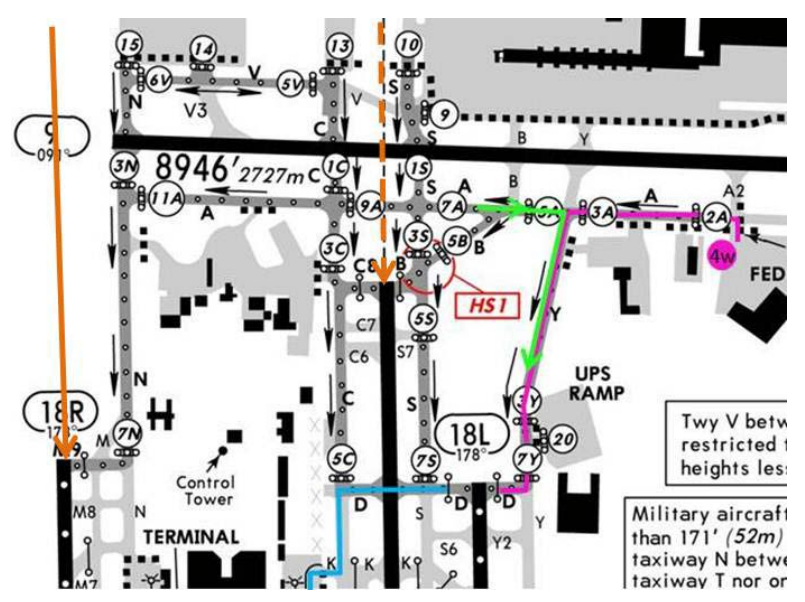

Figure 5. Taxi Head-On Conflict Scenario
At the beginning of this scenario, the ownship was parked on the ramp near Geographic Position Marker (GPM) 4W. The flight crew was cleared to taxi to Runway $18 \mathrm{~L}$ via Taxiways A2, A, Y, and D (Figure 5, magenta route). As the ownship taxied on Taxiway A, an aircraft was taxiing toward the ownship on Taxiway A. Provided the flight crews of both aircraft followed the STBO guidance, the aircraft would collide at the intersection of Taxiways $\mathrm{A}$ and $\mathrm{Y}$.

\section{Taxi Intersection Conflict Scenario}

In this scenario, both aircraft were given STBO taxi clearances that were conflict free, but the failure of the traffic aircraft to comply with the taxi clearance resulted in a taxiway intersection conflict.

The same approach and departure flow as previous was used.

At the beginning of this scenario, the ownship was parked on the ramp near GPM 4W. The flight crew was cleared to taxi to Runway $18 \mathrm{~L}$ via Taxiways A2, A, B, S, and D (Figure 6, magenta route). As the ownship taxied on Taxiway $A$, an aircraft was taxiing on Taxiway S from GPM 10, toward Taxiway A. The aircraft was given clearance to taxi to the terminal via Taxiways $\mathrm{S}, \mathrm{A}$, and $\mathrm{N}$ (Figure 6, green route). However, the flight crew blunders and continues straight on Taxiway S instead of turning onto Taxiway A. The aircraft conflicts with the ownship at the intersection of Taxiways $\mathrm{S}$ and $\mathrm{B}$, provided the flight crew followed their STBO guidance.

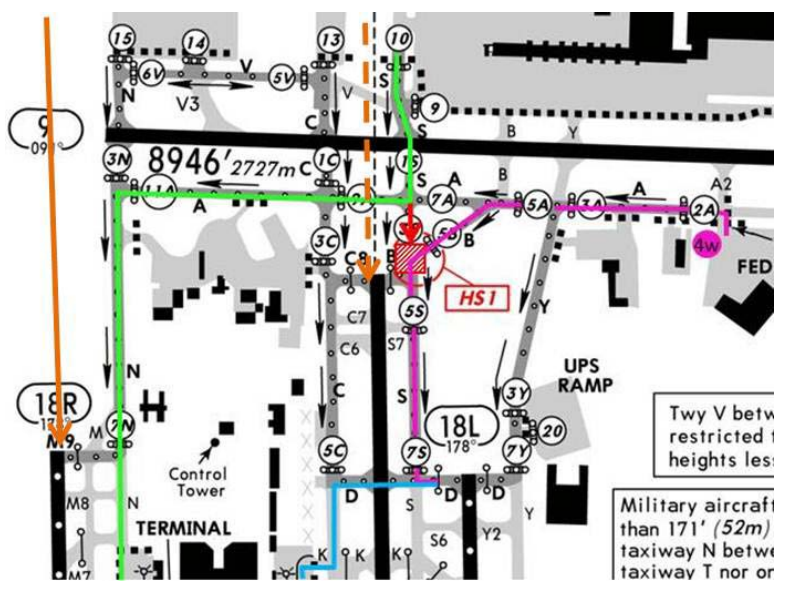

Figure 6. Taxi Intersection Conflict Scenario 


\section{Procedure}

Prior to the testing phase, each test subject participated in a briefing and training session.

During the training for the CD\&R capability, the flight crews were trained to stop if a warning alert was generated during taxi. They were not required to take evasive action when a caution alert was issued.

Before each trial, the flight crew was briefed on the run conditions, e.g., departure runway, HUD utilization, and ATC radio frequencies.

STBO taxi operations began in the ramp area with an expected taxi clearance received by the ownship via data-link. An example data-link expected taxi clearance is as follows: "EXPECT TAXI TO RWY 36C FROM SPOT 30 VIA C, E, J, R WITH EXPECTED TAXI RELEASE TIME 12:32:00Z. MONITOR GROUND 121.9." The expected taxi clearance was displayed as a dotted magenta line on the AMM. After acknowledging the expected taxi clearance by data-link, the flight crew taxied to the indicated GPM (also known as spot). After reaching the GPM, the actual taxi clearance was received via voice and data-link instructions. An example taxi clearance was: "TAXI RWY 36C BY 12:37:30Z VIA L-S-R. CROSS RWY 36C. TAXI RELEASE TIME 12:32:00Z." The taxi clearance was displayed as a solid magenta line on the AMM. The crew was required to respond to the taxi clearance via voice and data-link. The crew was to begin taxi as close as possible to the taxi release time and notify ATC they were commencing taxi. Once taxi began, the flight crew was requested to follow the taxi clearance and STBO guidance provided on the AMM and HUD, if utilized. The crews were instructed that acceptable performance was obtained if their RTA was met within $+/-15$ seconds. The trial terminated once the aircraft stopped at the runway hold line.

The test runs were documented via audio, video, and digital data recordings, and post-run and post-test questionnaires.

\section{Test Metrics}

For conflicts, a near-collision was counted if the center-of-gravity (CG) of the two aircraft were $<185$ $\mathrm{ft}$ apart laterally. A collision was counted if the aircraft CGs were $<150 \mathrm{ft}$ apart laterally.

\section{Results}

A summary of quantitative and qualitative results is presented. All data are referenced from the aircraft CG. The data was analyzed using parametric and non-parametric statistics, as appropriate, using an apriori level of significance of 0.05 .

\section{STBO Taxi Conformance Results}

Conformance in following STBO taxi guidance was evaluated by comparing actual performance against planned guidance at various locations along the cleared STBO taxi route. The following locations were evaluated for conformance: route start, straight segment mid-points, entering and exiting 90 degree turns, and route end. These locations were chosen to ensure homogeneity across the scenarios for analysis purposes. The independent variables for this analysis were Map condition (Map C and Map D) and the absence or presence of a HUD showing STBO guidance information. The dependent measure was the conformance time in seconds which was displayed to the flight crew on the AMM as seconds early $(+)$ or late (-). Histograms are also included that present the conformance time grouped into 5 second bins.

\section{STBO Route Start Location}

The crew was instructed to begin taxi as close as possible to the taxi release time. The "route start" conformance time measurement was taken when the aircraft CG crossed the hold line near the GPM.

Data for all 72 STBO test trials but one (nominal and off-nominal) were analyzed for start location conformance. Data for one crew was considered an outlier and omitted because the crew held for traffic in the ramp area before taxiing to the designated GPM, causing them to miss the release time. In all other test runs, the crew taxied to the GPM prior to the release time and could begin the trial in a timely manner.

After the taxi release time occurred, it took time for the engines to spool up and the aircraft to begin moving. As a result, for all test trials, the conformance measurement at the start location was always negative (Figure 7), i.e., late in comparison to the planned STBO guidance. The flight crews were within $+/-15$ seconds of the planned STBO release 
time on $54.9 \%$ (39 of 71 ) of the trials. The $95^{\text {th }}$ percentile data was between 7.8 and 20 seconds late. No significant effects were found for Map condition, HUD, or Map by HUD interaction.

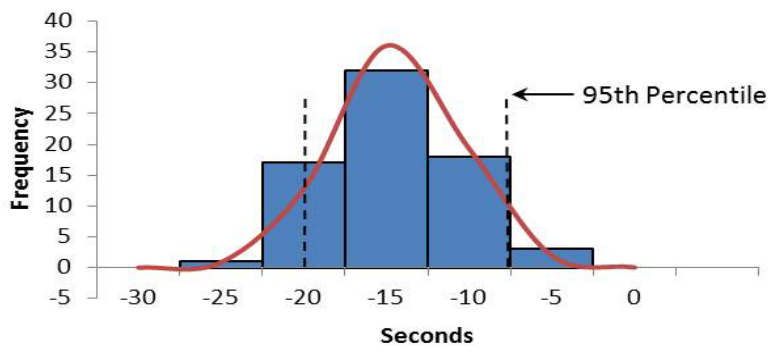

\section{Figure 7. STBO Route Start Location Conformance}

Many pilots made comments regarding starting out with a late conformance time. As a result, some pilots started advancing the throttles slightly before the release time to begin engine spool up earlier on later trials. Future STBO designs need to incorporate more latency in crew and aircraft spool-up at the start of the STBO route.

\section{STBO Straight Segment Mid-Point Locations}

For this measurement, the conformance time was taken near the mid-point of a straight taxi segment. Some cleared STBO taxi routes only had one straight segment while others had multiple straight segments. Data for all STBO test trials (nominal and off-nominal) were analyzed for the straight segment mid-point location (a total of 108 data points).

In general, the flight crews were able to conform well to the STBO guidance during the straight taxi segments (Figure 8). The crews were able to maintain $+/-10$ seconds of the guidance at the straight segment mid-point location $86.1 \%$ (93 of 108) of the time and $+/-15$ seconds for $92.6 \%$ (100 of 108) of the time.

There was a significant main effect found for HUD condition. Pilots had significantly better STBO guidance conformance, on the straight route segments, using a HUD (mean, $\mu,=1.1 \mathrm{sec}$, standard deviation, $\sigma,=11.3 \mathrm{sec}$ ) than without using a HUD $(\mu=-2.6 \mathrm{sec}, \sigma=7.9 \mathrm{sec})$.

In the straight-segments, crews were able to adjust their speed to meet their RTA. When viewed as conformance along the route, the data shows relatively good performance ( $92.6 \%$ compliance) but with some very significant tails in the data (i.e., one $\sim 50$ seconds early and several $\sim 30$ seconds late). Along route conformance was suboptimal in these cases since the crews were only asked to meet the end-of-route RTA performance. Intermediate/ waypoint RTAs were not used.

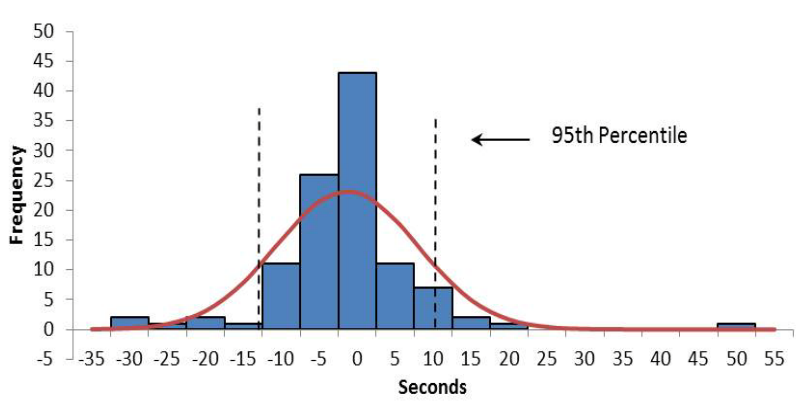

Figure 8. STBO Straight Segment Location Conformance

\section{STBO 90 Degree Turn Locations}

To analyze STBO performance during 90 degree turns, conformance time was taken 20 seconds prior to the center of the turn and 20 seconds after the center of the turn based on the planned route guidance. Some cleared STBO taxi routes only had one 90 degree turn while others had multiple 90 degree turns. Data for only nominal STBO test trials were analyzed because the off-nominal scenarios did not contain any 90 degree turns.

Of the 96 data points available, only 90 were included in the analysis. On three trials using the Map D condition, a wrong turn was made and data were not available. (After discussing the error with the crews, it was determined that the Captains mistakenly thought that their aircraft was at the location of the trend symbol instead of the white chevron and, as a result, turned early.) For three other trials, one turn produced the outliers. The ownship was taxiing on Taxiway $\mathrm{C}$ for a turn onto Taxiway $\mathrm{A}$. Another aircraft was taxiing along Taxiway A. On these three occasions, the ownship STBO conformance was late approaching the turn and the crew did not think the turn could be made onto Taxiway A in advance of the other aircraft; therefore, they held for the other traffic and thus, were very late entering the turn. Since performance was 
significantly different than on the other trials, these data were omitted as outliers.

There was a wide variability for conformance at the entry and exit location of the 90 degree turns (Figures 9 and 10). The STBO guidance was reduced to $4 \mathrm{kts}$ on most 90 degree turns. This is apparently slower than turns are usually taken because, in general, the actual speed during the turns (center of turn) was higher ( $\mu=9.5 \mathrm{kts}, \sigma=2.7 \mathrm{kts})$ than the advised speed ( $\mu=4.5 \mathrm{kts}, \sigma=1.4 \mathrm{kts})$ and, as a result, conformance time at the exit location was earlier $(\mu=9.5 \mathrm{sec}, \sigma=13.6 \mathrm{sec})$ than conformance time at the entry location $(\mu=0.9 \mathrm{sec}, \sigma=13.9 \mathrm{sec})$. The entry location was reached early $51.1 \%$ (46 of 90) of the time, while the exit location was reached early $77.8 \%$ (70 of 90) of the time. As some of the pilots realized that the planned speed was very slow in the turns, they began going into them late so the turn could be taken faster. Many pilots commented that the STBO speed guidance in the turns was too slow and, for a transport category aircraft, should be 8 to $10 \mathrm{kts}$.

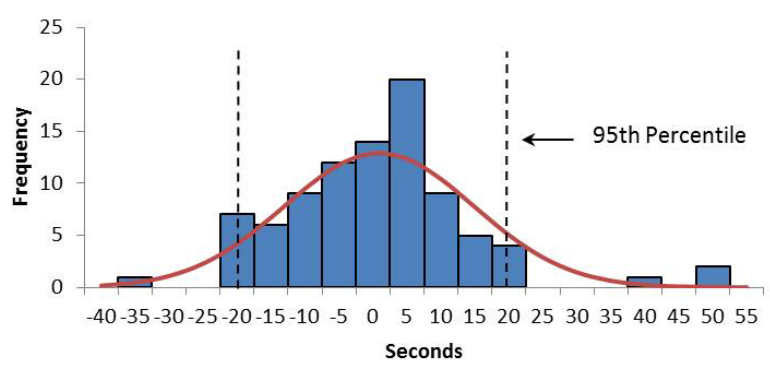

Figure 9. STBO Enter 90 Degree Turn Location Conformance

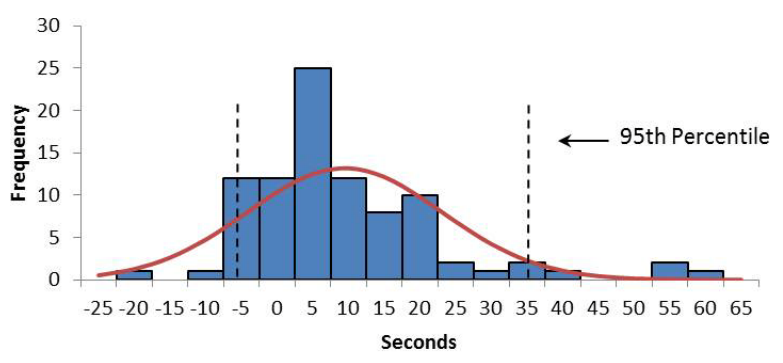

Figure 10. STBO Exit 90 Degree Turn Location Conformance

When entering a 90 degree turn, the flight crews maintained +/- 15 seconds of the planned STBO guidance on $78.9 \%$ (71 of 90 ) of the turns. No significant effects were found.

When exiting a 90 degree turn, the flight crews maintained +/- 15 seconds of the planned STBO guidance on $73.3 \%$ (66 of 90 ) of the turns. No significant effects were found.

\section{STBO Route End Location}

The goal of providing STBO guidance was to enable flight crews to reach the end of the taxi route at the RTA. This "RTA point" was shown on the $\mathrm{AMM}$ as a green diamond near the end of the cleared route. The conformance time measurement was taken when the aircraft CG crossed the RTA point. Data for only nominal STBO test trials were analyzed because the RTA point was never reached during the offnominal trials.

Of the 48 data points available, only 47 were included in the analysis. On one trial, the crew slowed to conduct the before takeoff checklist just before crossing the RTA point, making the conformance time very late $(-27$ seconds). Since performance was significantly different than on the other trials, this data was omitted as an outlier.

STBO route end location data is presented in Figure 11. On 97.9\% (46 of 47) of the trials, the RTA point was crossed within $+/-10$ seconds of the RTA, and within $+/-5$ seconds of the RTA on $87.2 \%$ (41 of $47)$ of trials. The crews were instructed that acceptable performance was met if the RTA point was reached within +/- 15 seconds of the RTA; these data show excellent compliance to this goal.

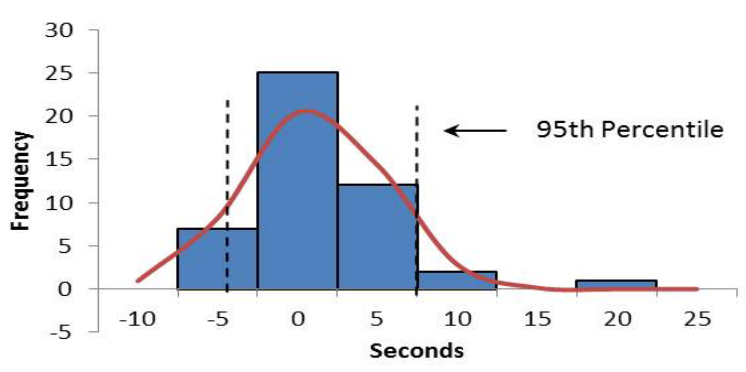

Figure 11. STBO Route End Location Conformance

On the one trial in which the 15 second requirement was not met, the crew was focused on oncoming traffic near the taxi route and crossed the 
RTA point 20 seconds early. No significant effects were found.

The STBO data shows that intermediate performance could vary significantly but the crews met their instructed goal - the end route RTA. If compliance along the route is necessary, intermediate RTAs/waypoints will be needed. The data also shows that STBO guidance development is not and may never be a trivial task. An STBO RTA significantly impacts air carrier Standard Operating Procedures (SOPs) and crew procedures (e.g., influencing when checklists can be started and completed), taxi speeds (including how this may vary by aircraft type and aircraft loading) and how they vary with traffic, taxi route (e.g., turns, hot spots) and prevailing visibility, and passenger comfort (e.g., how quickly to turn, accelerate, and decelerate).

\section{Off-Nominal Scenario Results}

As described in the Test Method section, the offnominal trials were conducted between subjects to evaluate collision avoidance capability during STBO. The focus of the off-nominal scenarios was to determine the usefulness of traffic intent information for taxi collision avoidance and to determine the usefulness of CD\&R for collision avoidance during
STBO. Each crew evaluated the off-nominal scenarios using either the Map C or D condition with conflict traffic transmitting either NACp 9 or NACp 10 position accuracy; therefore, three data points were collected for each combination of conditions. Intent information was displayed graphically on Map D but only textually on Map C. Alerts were not issued for traffic transmitting NACp 9 position accuracy, but were issued for traffic transmitting NACp 10 position accuracy. Since all traffic on the airport was transmitting position accuracy of NACp 9 and higher, all traffic was displayed on the AMM.

\section{Taxi Head-On Conflict Scenario Results}

The taxi head-on scenario was given as Trial 3 of six trials for each crew. This scenario simulated faulty SBTO guidance where conflicting traffic would meet the ownship head-on at an intersection, if the ownship followed the STBO guidance.

For all of the taxi head-on trials, the ownship either slowed down or stopped for traffic to turn ahead of them at the intersection, averting a collision or conflict (Table 2). The flight crew was aware of the conflict traffic on each trial by either viewing the traffic intent information or viewing the traffic OTW. It was relatively easy to visually acquire the traffic OTW since the visibility was $1,800 \mathrm{ft}$.

Table 2. Taxi Head-On Scenario Results

\begin{tabular}{|c|c|c|c|c|c|}
\hline Map & NACp & Action & Outcome & CPA (feet) & Viewed Intent \\
\hline C & 9 & Stopped & & 202.1 & Yes \\
\hline C & 9 & Slowed & & 274.0 & Yes \\
\hline C & 9 & Stopped & & 275.8 & Yes \\
\hline C & 10 & Slowed & & 317.4 & Yes \\
\hline C & 10 & Slowed & Near-collision & 213.4 & Yes \\
\hline C & 10 & Slowed & Near-collision & 186.6 & Yes \\
\hline D & 9 & Slowed & & 384.5 & Yes \\
\hline D & 9 & Stopped & & 268.8 & Yes \\
\hline D & 9 & Stopped & & 213.2 & Yes \\
\hline D & 10 & Slowed & Near-collision & 222.2 & Yes \\
\hline D & 10 & Stopped & & 333.6 & Yes \\
\hline D & 10 & Stopped & & 319.3 & Yes \\
\hline
\end{tabular}

Alerts were possible on the conflict traffic on six taxi head-on trials (i.e., NACp 10). Nine caution alerts were generated for six trials prior to reaching the conflict intersection, at an average distance of 577 $\mathrm{ft}$ from the traffic $(\sigma=300 \mathrm{ft})$. The caution alert was generated earlier when the ownship was traveling faster. Multiple alerts were issued for two crews. (No provisions were made to reduce the occurrence of alert toggling which occurs when multiple instances of alerts are generated as a result of position accuracy or aircraft maneuvering. Alert toggling can be a distraction to the flight crew and could cause mistrust in the technology.) A warning alert was also 
generated on all three trials, $268 \mathrm{ft}$ mean distance from the traffic $(\sigma=15 \mathrm{ft})$.

Three trials where traffic was transmitting NACp 10 accuracy (i.e., with alerts generated) resulted in near-collisions per our criteria. The nearcollision calculation was made by determining whether the aircraft CGs were separated by less than $185 \mathrm{ft}$ laterally; which is different than the closestpoint-of-approach (CPA) calculation (slant range). Two of the near-collisions occurred at the conflict intersection because the pilot slowed instead of stopping and eventually met the near-collision criteria. The third near-collision occurred when taxiing behind the conflict traffic after turning at the conflict intersection. The subject crew had gotten behind in following the STBO guidance while waiting for the conflict traffic to turn ahead, and was trying to reacquire the STBO planned timing but, because they were judging separation distance visually, met the near-collision criteria.

After turning at the subject intersection, alerts were generated while following the taxiing conflict traffic. The pilots were trying to reacquire their STBO conformance and taxied close enough to the traffic to generate alerts. Four caution alerts were generated for three trials, at an average distance of $280 \mathrm{ft}$ from the traffic $(\sigma=83 \mathrm{ft})$. One warning alert was generated on one trial $222 \mathrm{ft}$ from the traffic.
Alerts were not generated for any other traffic during these off-nominal trials.

\section{Taxi Intersection Conflict Scenario Results}

The taxi intersection scenario was given as Trial 6 of six trials for each crew. This scenario simulated a blunder with the conflicting traffic missing its planned turn and instead, incurring from the right of the ownship, if the ownship followed the STBO guidance.

One or both pilots were aware of the conflict traffic on each trial by either viewing the traffic symbol or traffic intent on the AMM or viewing OTW. For 10 of the taxi intersection trials, the ownship either slowed down or stopped for the taxiing traffic prior to the intersection (Table 3). On two trials, the pilots were early in following their STBO planned guidance ( 8 and 10 seconds) at the intersection, they were aware of the conflict traffic and they knew the aircraft missed its turn. The crews decided to speed up and turn in front of the traffic. The automated conflict traffic taxiing from behind overran the ownship causing the two collisions. Alerts were not generated for the conflict traffic on these two trials because the traffic was transmitting NACp 9 accuracy.

Table 3. Taxi Intersection Scenario Results

\begin{tabular}{|c|c|c|c|c|c|}
\hline Map & NACp & Action & Outcome & CPA (feet) & Viewed Intent \\
\hline C & 9 & Stopped & & 303.9 & Yes \\
\hline C & 9 & Slowed & Near-collision & 214.6 & Yes, late \\
\hline C & 9 & Stopped & Near-collision & 251.7 & Yes \\
\hline C & 10 & Stopped & & 262.9 & Yes \\
\hline C & 10 & Stopped & Near-collision & 170.4 & $\begin{array}{c}\text { No, stopped based on } \\
\text { caution }\end{array}$ \\
\hline C & 10 & Stopped & & 220.5 & $\begin{array}{c}\text { Yes, stopped based on } \\
\text { caution }\end{array}$ \\
\hline D & 9 & Turned in front & Collision & 36.2 & Yes \\
\hline D & 9 & Turned in front & Collision & 42.2 & Yes \\
\hline D & 9 & Stopped & Near-collision & 179.7 & Yes, early \\
\hline D & 10 & Stopped & & 303.0 & Yes \\
\hline D & 10 & Stopped & & 268.9 & Yes \\
\hline D & 10 & Stopped & & 235.4 & Yes, early \\
\hline
\end{tabular}

Four trials resulted in near-collisions. Three of the near-collisions occurred at the conflict intersection. The fourth near-collision occurred when taxiing behind the conflict traffic after turning at the conflict intersection. The ownship taxied very close to the traffic near the end of the route, trying to cross 
the RTA point. Only one near-collision occurred on the trials in which alerts were generated.

Alerts were possible on six of the taxi intersection trials (NACp 10). A caution alert was generated for each of the six trials prior to reaching the conflict intersection, at an average distance of 460 $\mathrm{ft}$ from the traffic $(\sigma=32 \mathrm{ft})$. A warning alert was also generated on four of the trials, $265 \mathrm{ft}$ mean distance from the traffic $(\sigma=7 \mathrm{ft})$.

After turning at the subject intersection, alerts were generated while following the conflict traffic. The pilots were trying to reacquire their STBO conformance and taxied close enough to the traffic to generate alerts. Three caution alerts were generated for two trials, at an average distance of $410 \mathrm{ft}$ from the traffic $(\sigma=123 \mathrm{ft})$. Multiple alerts were issued for one crew. One warning alert was generated on one trial $290 \mathrm{ft}$ from the traffic.

Alerts were not generated for any other traffic during these off-nominal trials.

\section{Qualitative Results}

Post-run and post-test questionnaires were administered. Most of the questions were rated on a scale of 1 ("strongly disagree", "low", "not useful") to 7 ("strongly agree", "high", "very useful”).

STBO - The pilots were neutral in rating STBO for increasing workload compared to current surface operations $(\mu=4.2, \sigma=1.9)$; however, they did feel that STBO would increase their general situation awareness $(\mu=6.2, \sigma=1.2)$. They moderately agreed that STBO will increase efficiency $(\mu=5.0, \sigma=1.6)$ and safety $(\mu=5.0, \sigma=2.0)$ for ground movement of aircraft. Pilots generally commented that STBO negatively impacts workload and reduces the ability to watch for other traffic. Additional comments were STBO can be distracting; takes one pilot out of the loop; realistic taxi speed and parameters should be utilized as aircraft performance differs, large aircraft must consistently manage their energy and momentum; and STBO works in a "sterile" environment, taxi operations differ among fleets and airports. Concerns were expressed regarding how the STBO system will account for routing modifications, STBO guidance non-compliance, and taxi errors.
STBO Symbology - Pilot ratings indicated that STBO would cause a moderate increase in headdown time compared to current-day operations $(\mu=$ $4.8, \sigma=2.0)$. Pilots commented that STBO caused more heads-down time than normal. The pilots felt that STBO information should be located on the AMM on the ND (18 pilots), HUD (15 pilots), and an AMM located on the EFB (14 pilots); however, they did not feel STBO information should be on the PFD (3 pilots) (pilots were requested to select all that were required).

The Captains agreed that the advised ground speed information on the HUD was useful $(\mu=5.8, \sigma$ $=1.8$ ); however, they also felt that the advised ground speed alone, without any other STBO guidance information, was not optimal $(\mu=3.6, \sigma=$ 2.0). Many pilots recommended also displaying the RTA time deviation (seconds early/late) on the HUD.

Pilots that used Map Condition $\mathrm{C}$ indicated that it was easy to tell if they were going to reach the guidance end point on time, ahead of time, or behind schedule $(\mu=6.4, \sigma=0.9)$. All STBO symbology elements were rated as being useful, including the selected traffic information $(\mu=5.6, \sigma=1.6)$.

Pilots that used Map Condition D also indicated that it was easy to tell if they were going to reach the guidance end point on time, ahead of time, or behind schedule $(\mu=6.0, \sigma=1.1)$. All STBO symbology elements were rated as being useful including the graphical traffic intent information $(\mu=6.5, \sigma=0.7)$ and graphical STBO guidance $(\mu=5.8, \sigma=1.5)$. They felt that the graphical traffic intent information (traffic taxi route and guidance circles) was useful for determining the intent of aircraft $(\mu=6.0, \sigma=1.2)$. The pilots were neutral regarding the usefulness of the selected (textual) traffic information $(\mu=4.4, \sigma=$ 2.0), thus, implying a preference for graphical information. However, the graphical symbology was also confusing to some as evidence by two crews misinterpreting the symbology.

$C D \& R$ Symbology and STBO - The pilots agreed that the $C D \& R$ system was effectively integrated with the STBO display concepts $(\mu=5.8, \sigma=1.0)$ and that CD\&R was effective during STBO $(\mu=5.5$, $\sigma=1.1$ ). The pilots slightly agreed that the traffic intent information was useful in identifying traffic conflict situations when using either map condition (Map C, $\mu=5.3, \sigma=1.8$; Map D, $\mu=5.7, \sigma=1.9$ ). 


\section{Summary}

A piloted simulation study was conducted to evaluate the ability to safely conduct STBO by assessing the impact of providing traffic intent information, CD\&R system capability, and the display of STBO guidance to the flight crew on both a head-down display and HUD.

STBO was a new concept for the test subjects. On 98 percent of the trials, the flight crews met their RTA at the end of the taxi route within +/- 10 seconds, well within the acceptable performance bounds of $+/-15$ seconds of RTA. They also had very good STBO conformance during straight taxi segments, on $93 \%$ of the trials the crews were within $+/-15$ seconds of the planned guidance. However, some of the design aspects of STBO (slow start-up at the release time, slow speeds in turns) were quickly identified by the crews and some of the pilots started advancing the throttles slightly before the taxi release time and 'gaming' the turns (i.e., going into them late so the turn could be taken faster). Conformance, therefore, varied widely at these locations.

If compliance along the route is necessary, explicit intermediate RTAs/waypoints will be needed. Effective STBO will also need to account for SOPs, crew procedures, aircraft type and aircraft loadings, traffic, taxi route, prevailing visibility, and passenger comfort.

The display of traffic intent information was found to be helpful, particularly to the first officer. Graphical presentation of intent was preferred over textual presentation; however, the method of presentation must be optimized in either case. The current graphical implementation was the cause of three wrong turns because the pilot mistakenly thought that their aircraft was at the location of the intent symbology.

The CD\&R system was minimally effective during STBO because the traffic was visible out-thewindow $(1,800 \mathrm{ft}$ visibility). The flight crews were always aware of the traffic prior to any alerts being generated. Interestingly, two collisions occurred because the flight crews were early in reaching the intersection and turned in front of traffic; subsequently, the traffic taxied into the ownship. Alerts were not generated on these aircraft, so perhaps the crew was more willing to proceed ahead of the traffic. In some instances, alerts were issued when the ownship was following the traffic after turning at the intersection.

Overall, the test subjects were neutral regarding the ability of STBO to increase efficiency. The pilots expressed concern for increased workload, the ability to watch for other traffic, and increased head-down time. Although not evaluated, pilots expressed concerns regarding how an STBO system will account for modifications to routing, STBO guidance non-compliance, and taxi errors.

\section{References}

[1] Joint Planning \& Development Office, 2010, Concept of Operations for the Next Generation Air Transportation System, Version 3.2, Washington, DC.

[2] Jung, Y., T. Hoang, J. Montoya, G. Gupta, W. Malik, L. Tobias, and H. Wang, 2011, Performance Evaluation of a Surface Traffic Management Tool for Dallas/Fort Worth International Airport, Ninth USA/Europe Air Traffic Management Research and Development Seminar (ATM2011).

[3] Jung, Y. C., T. Hoang, J. Montoya, G. Gupta, W. Malik, and L. Tobias, 2010, A Concept and Implementation of Optimized Operations of Airport Surface Traffic, $10^{\text {th }}$ AIAA Aviation Technology, Integration, and Operations (ATIO) Conference.

[4] Foyle, D. C., B. L. Hooey, C. L. Kunkle, F. J. Schwirzke, and D. L. Bakowski, 2009, Piloted Simulation Of NextGen Time-based Taxi Clearances and Tailored Departures, Proceedings of the 2009 IEEE/AIAA Integrated Communications, Navigation and Surveillance Conference.

[5] Prinzel, L. J., D. R. Jones, K. J. Shelton, J. J. Arthur, R. E. Bailey, A. S. Allamandola, D. C. Foyle, and B. L. Hooey, 2009, Flight Deck Display Technologies for 4DT and Surface Equivalent Visual Operations, Proceedings of the $15^{\text {th }}$ International Symposium on Aviation Psychology.

[6] Shelton, K. J.; L. J. Prinzel, D. R. Jones, J. J. Arthur, A. S. Allamandola, and R. E. Bailey, 2009, Surface Map Traffic Intent Displays and Net-Centric Data-Link Communications for NextGen, 
Proceedings of the $28^{\text {th }}$ Digital Avionics Systems Conference.

[7] Cheng, V. H. L., A. D. Andre, and D. C. Foyle, 2009, Information Requirements for Pilots to Execute 4D Trajectories on the Airport Surface, 2009 AIAA Aviation Technology, Integration, and Operations (ATIO) Conference.

[8] Foyle, D. C., B. L. Hooey, D. L. Bakowski, J. L. Williams, and C. L. Kunkle, 2011, Flight Deck Surface Trajectory-based Operations (STBO) Simulation Results and ConOps Implications, Ninth USA/Europe Air Traffic Management Research and Development Seminar, ATM2011.

[9] Jones, D. R., C. C. Quach, and S. D. Young, 2001, Runway Incursion Prevention System Demonstration and Testing at the Dallas/Fort Worth International Airport, Proceedings of the $20^{\text {th }}$ Digital Avionics Systems Conference, Daytona Beach, FL.

[10] Jones, D. R., 2002, Runway Incursion Prevention System Simulation Evaluation, Proceedings of the AIAA/IEEE $21^{\text {st }}$ Digital Avionics Systems Conference. Irvine, CA.

[11] Jones, D. R., 2005, Runway Incursion Prevention System Testing at the Wallops Flight Facility, Proceedings of the SPIE Defense \& Security Symposium, Enhanced and Synthetic Vision 2005, Vol. 5802, pp. 47-58.

[12] Jones, D. R., L. J. Prinzel, K. J. Shelton, R. E. Bailey, S. D. Otero, and G. D. Barker, 2010, Collision Avoidance for Airport Traffic Simulation Evaluation, Proceedings of the 29th Digital Avionics Systems Conference, Salt Lake City, UT.

[13] Jones, D. R., R. C. Chartrand, S. R. Wilson, S. A. Commo, S. D. Otero, and G. D. Barker, 2012, Airport Traffic Conflict Detection and Resolution Algorithm Evaluation, Proceedings of the 31st Digital Avionics Systems Conference, Williamsburg, VA.

[14] Cheng, V. H. L., V. V. S. S. Vaddi, and Sweriduk, G. D., 2011, Surface Conflict Detection and Resolution with Emphasis on Trajectory-Based Operations, Base Year Final Report, NASA NRA Contract No. NNA10DE59C.
[15] Montoya, J., R. Windhorst, Z, Zhu, S. Gridnev, K. J. Griffen, A. Saraf, and S. Stroiney, 2013, Analysis of Airport Surface Schedulers Using FastTime Simulation, 2013 Aviation Technology, Integration, and Operations (ATIO) Conference.

[16] Cheng, V. H. L., V. V. S. S. Vaddi, J. Kwan, S. Wiraatmadja, A. Fong, J. Rife, and F. Saunders, 2012, Surface Conflict Detection and Resolution with Emphasis on Trajectory-Based Operations, Option Year 1 Final Report, NASA NRA Contract No. NNA10DE59C.

[17] Federal Aviation Administration, 2007, Electronic Flight Deck Displays, Advisory Circular 25-11A, Washington, DC.

[18] RTCA, Inc., 2001, User Requirements for Aerodrome Mapping Information, RTCA DO-272, Washington, DC.

[19] RTCA, Inc., 2010, Safety, Performance and Interoperability Requirements Document for Enhanced Traffic Situational Awareness on the Airport Surface with Indications and Alerts (SURF IA), DO-323, Washington, DC.

[20] Otero, S. D., G. D. Barker, and D. R. Jones, 2013, Initial Concept for Terminal Area Conflict Detection, Alerting, and Resolution Capability On or Near the Airport Surface, Version 2.0, NASA TM2013-218052, NASA Langley Research Center, Hampton, VA.

[21] Mohleji, S. C., and G. Wang, 2010, Modeling ADS-B Position and Velocity Errors for Airborne Merging and Spacing in Interval Management Application, MITRE release \# 10-3026.

[22] RTCA, Inc., 2002, Minimum Aviation System Performance Standards for Automatic Dependent Surveillance Broadcast (ADS-B), DO-242A, Washington, DC.

[23] RTCA, Inc., 2003, Minimum Aviation System Performance Standards for Aircraft Surveillance Applications (ASA), DO-289, Washington, DC.

[24] RTCA, Inc., 2010, Safety, Performance and Interoperability Requirements Document for ATSASURF Application, DO-322, Washington, DC. 


\section{Acknowledgements}

The authors would like to express their appreciation to LaRC Simulation Development and Analysis Branch personnel for their support throughout all phases of implementation and testing and to NASA's Aviation Safety Program for sponsoring this research. 33rd Digital Avionics Systems Conference

October 5-9, 2014 